
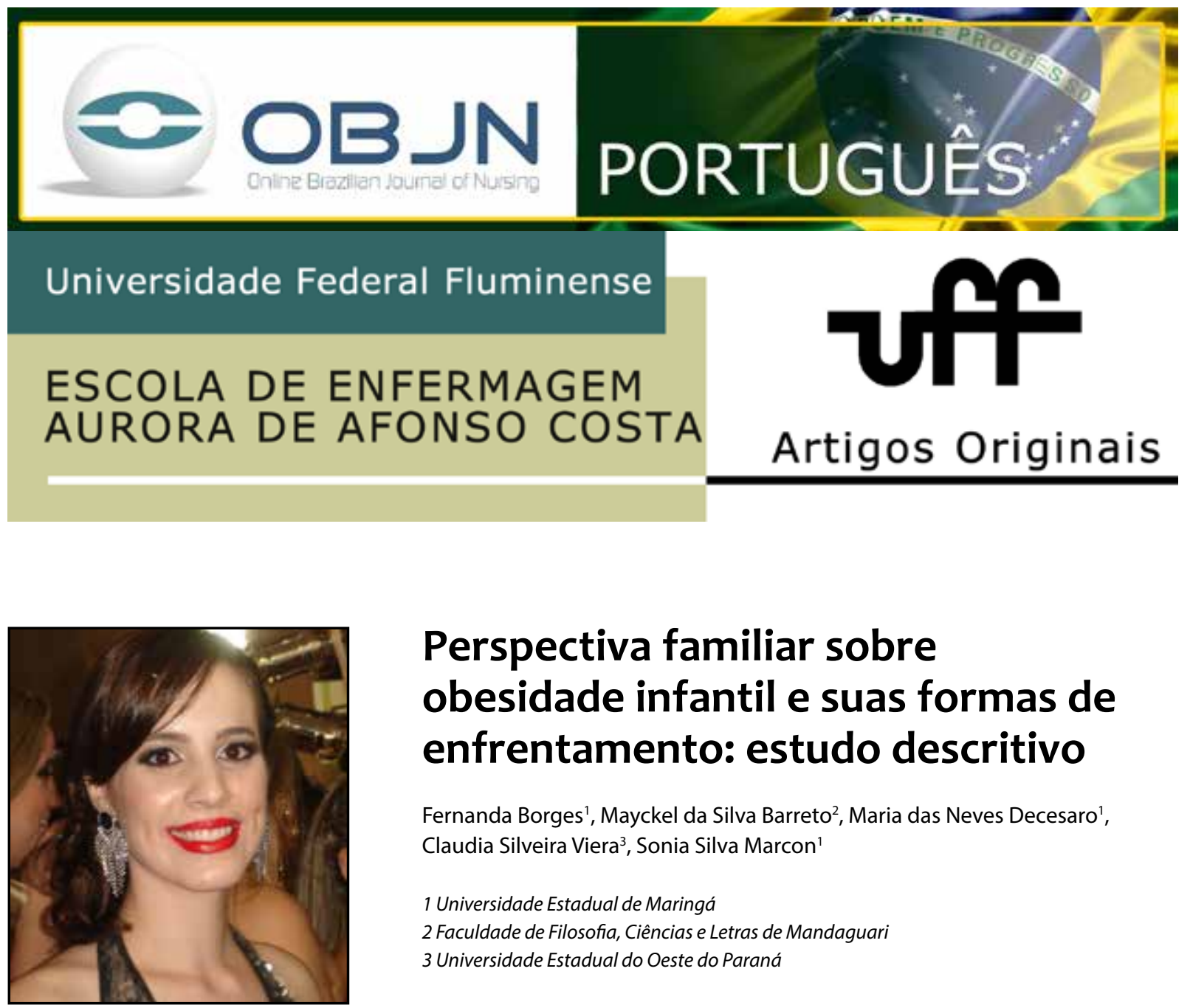

\title{
Perspectiva familiar sobre obesidade infantil e suas formas de enfrentamento: estudo descritivo
}

\author{
Fernanda Borges ${ }^{1}$, Mayckel da Silva Barreto², Maria das Neves Decesaro', \\ Claudia Silveira Viera ${ }^{3}$, Sonia Silva Marcon ${ }^{1}$ \\ 1 Universidade Estadual de Maringá \\ 2 Faculdade de Filosofia, Ciências e Letras de Mandaguari \\ 3 Universidade Estadual do Oeste do Paraná
}

\section{RESUMO}

Objetivo: identificar como a família percebe a saúde da criança com obesidade e quais as estratégias adotadas para o seu enfrentamento. Método: pesquisa descritiva de abordagem qualitativa. Os dados foram coletados entre janeiro e maio de 2014 por meio de entrevistas com 14 mães de crianças obesas. As falas foram submetidas à Análise de Conteúdo, Modalidade Temática. Resultados: observou-se que algumas famílias não reconheciam a obesidade como problema de saúde, enquanto que outras identificavam complicações. O estímulo a hábitos alimentares saudáveis e prática de atividades físicas constituíam as principais estratégias de enfrentamento adotadas pelas famílias. Entretanto, por vezes, algumas práticas prejudicavam a saúde. Conclusão: a família parece reconhecer a obesidade infantil como um problema de saúde quando a criança apresenta complicações, e, neste momento, passa a enfrentá-la. Profissionais de saúde devem estar atentos às diferentes formas de entendimento e enfrentamento da obesidade infantil para que possam atuar de maneira qualificada.

Descritores: Obesidade Pediátrica; Relações Familiares; Enfermagem Pediátrica; Estilo de Vida; Saúde Pública. 


\section{INTRODUÇÃO}

A obesidade atualmente constitui problema de saúde pública nos países com alto poder econômico e também naqueles menos favorecidos, em que a desnutrição e o baixo peso eram mais evidentes ${ }^{(1)}$. Ademais, a obesidade tem surgido cada vez mais precocemente, refletindo no aumento expressivo de crianças com sobrepeso e obesidade ${ }^{(2)}$. Por exemplo, em 1990, eram 31 milhões (5\%) de crianças menores de cinco anos acima do peso e em 2012 já eram 44 milhões $(6,7 \%)^{(1)}$.

Crianças obesas possuem maiores chances de se tornarem adultos obesos ${ }^{(2)}$, além do que, esta condição de saúde se associa a uma diversidade de complicações graves e risco aumentado para doenças prematuras ${ }^{(1)}$. Com vistas a fomentar mudanças no cenário atual da obesidade infantil, faz-se necessário seu reconhecimento como problema de saúde pública, elaboração de ações preventivas e desenvolvimento de tratamentos eficazes ainda na infância.

Desta forma, a detecção precoce da obesidade, seu controle e tratamento devem abarcar todos os espaços sociais em que a criança está inserida, com ênfase no envolvimento familiar nesse processo ${ }^{(3)}$. Nos últimos anos, pesquisas foram produzidas abordando a percepção da família em relação ao estado nutricional infantil ${ }^{(3-5)}$, porém, ainda existem lacunas sobre a compreensão da família a respeito dessa doença e também no concernente às ações desenvolvidas no âmbito familiar para o enfrentamento da obesidade.

Diante disso, definiu-se como objetivo da presente pesquisa, identificar como a família percebe a saúde da criança com obesidade e quais as estratégias adotadas para o seu enfrentamento.

\section{MÉTODO}

Pesquisa descritiva, de abordagem qualitativa, realizada em um município de médio porte da região sul do Brasil, por meio de entrevista com o cuidador principal da criança obesa. Optou-se por realizar uma investigação qualitativa, pois seu foco está direcionado no indivíduo e na sociedade, com o objetivo de aprofundar o conhecimento sobre questões relacionadas ao cotidiano das pessoas, considerando-se as interpretações sobre suas vivências ${ }^{(6)}$. Assim, o fenômeno em estudo - entendimento e enfrentamento da obesidade infantil no seio familiar - poderia ser melhor compreendido por meio da abordagem qualitativa.

Para a seleção dos sujeitos da pesquisa utilizou-se o banco de dados do Sistema de Vigilância Alimentar e Nutricional (SISVAN) do município, o qual permitiu a localização de crianças com idade entre seis e dez anos incompletos classificadas como obesas. Este sistema recebe informações de 63 equipes da Estratégia Saúde da Família (ESF), atuantes nas 28 Unidades Básicas de Saúde (UBS) existentes no município, por ocasião da coleta de dados.

A partir das informações desse relatório, foi possível contatar os responsáveis pela criança, para que fossem convidados a participar da pesquisa. Neste momento, eles foram informados sobre os objetivos do estudo e a forma de participação desejada. O contato inicial com a família foi por telefone, e com aquelas que concordaram em participar, foi agendada, de acordo com a sua disponibilidade, uma visita domiciliar.

Para se proceder às entrevistas foi utilizado um roteiro constituído de cinco questões. Estas abordavam a percepção do estado de saúde atual da criança, a rotina alimentar da família e da criança, as atitudes que a família acreditava contribuir para a redução e/ou aumento de peso da criança e o conhecimento dela sobre o tema 
obesidade infantil. Também foi utilizada a escala visual de Tiggeman e Wilson-Barret ${ }^{(7)}$ com nove figuras representativas da condição ponderal da criança, sendo que a figura um correspondia ao baixo peso e a figura nove a uma criança com o maior grau de obesidade (Figura 1). Aos participantes foi solicitado apontar a figura que acreditavam corresponder a seu filho e aquela que gostariam que ele correspondesse.

Figura 1. Conjunto de Silhuetas para a avaliação da Imagem Corporal

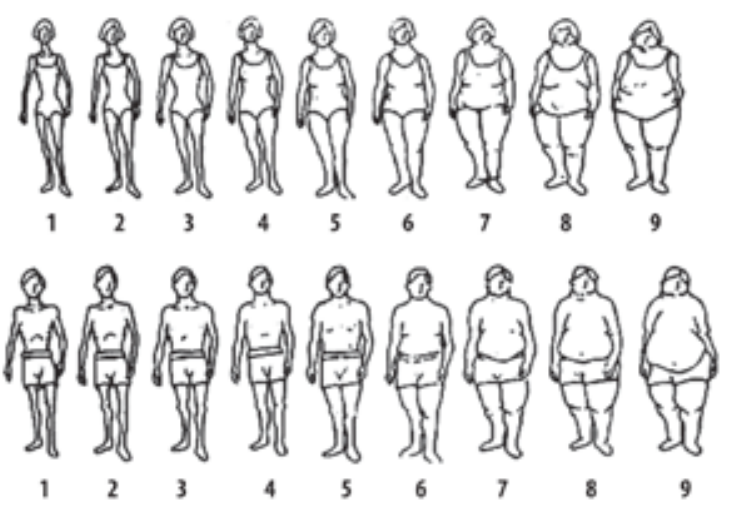

Fonte: Tiggemann e Wilson-Barret (1998) ${ }^{(7)}$

Obtendo-se a anuência dos familiares, as entrevistas foram gravadas. Em seguida, transcritas na íntegra e submetidas à análise de conteúdo, modalidade temática(6), envolvendo três etapas. Na primeira, a de pré-análise, ocorreu a organização do material a partir da leitura exaustiva dos relatos obtidos nas entrevistas. Na segunda etapa, a da exploração do material, foram recortadas as unidades de registro com a utilização de canetas coloridas para a identificação dos temas trabalhados. Por fim, na terceira etapa, interpretação dos resultados, os discursos foram confrontados com a literatura científica de modo a ampliar a compreensão do fenômeno.

$O$ estudo ocorreu em conformidade com as prerrogativas fixadas pela resolução 466/12 do Conselho Nacional de Saúde e aprovado pelo comitê permanente de ética em pesquisa envolvendo seres humanos da Instituição signa- tária (parecer $n^{\circ} 500.380$ ). Todos os participantes assinaram o termo de consentimento livre e esclarecido. Para preservar suas identidades, os discursos foram identificados pela ordem de realização da entrevista seguido pelas idades da mãe e do filho, conforme o exemplo: mãe 1, 28 anos - filho, 9 anos.

\section{RESULTADOS}

A partir do contato com o cuidador principal da criança foram informantes do estudo 13 mães e uma avó, com idade variando de 28 a 63 anos. Na identificação dos discursos, todas as respondentes foram consideradas mães, pois a única avó participante da pesquisa também exercia essa função para a criança. A análise dos discursos permitiu a identificação de duas categorias temáticas: "reconhecendo o estado de saúde da criança e as consequências da obesidade infantil"; e "desenvolvimento, manutenção e tratamento da obesidade infantil: o enfrentamento da família".

Reconhecendo o estado de saúde da criança e as consequências da obesidade infantil

Algumas mães não percebiam a obesidade como problema de saúde, nestes casos, faziam referência à presença de outras patologias como obstáculo para atingirem o estado de saúde desejável. Outras demonstraram reconhecer a condição de obesidade e a influência desta no estado de saúde de seus filhos.

$$
\begin{aligned}
& \text { Ela está bem, graças a Deus. Só tirando } \\
& \text { o problema da tireoide. Mas, isso vai } \\
& \text { no controle. Ela tinha um problema de } \\
& \text { rinite, mas também já operou há três } \\
& \text { anos e as amidalas também (Mãe 3, } 42 \\
& \text { anos - Filha, } 9 \text { anos). }
\end{aligned}
$$


Ela sempre foi saudável, agora é que está com diabetes, mas sempre foi uma criança saudável, nunca teve anemia e não ficava doente (Mãe 12, 30 anos Filha, 7 anos).

A mãe 5, justificou que pelo fato de o tratamento da obesidade ser comportamental, não a considera como uma doença. Para ela doença exige tratamento farmacológico, acompanhamento médico ou intervenção cirúrgica.

Eu não considero [a obesidade] uma doença, mas é crítico. Não é uma coisa assim normal, de dizer que não é nada. Mas, acho que não chega a ser doença, porque se você tiver uma mudança de comportamento você emagrece. Agora a doença, não é só mudança de hábito, você tem que tomar remédio, fazer tratamento, cirurgias... (Mãe 5, 31 anos - Filho, 9 anos).

A obesidade infantil era considerada doença somente quando atingia um grau mórbido, especialmente quando já estavam presentes algumas consequências ou nos casos em que as complicações começavam a se manifestar.

Não considero a obesidade uma doença. Sinceramente há casos e casos. Conheço criança da idade dela que é assim [demonstra colocando os dois braços distantes do corpo], neste caso, ela está se transformando em doença (Mãe 12, 30 anos - Filha, 7 anos).

No estudo ora apresentado, a maior parte das crianças ainda não possuía reflexos físicos negativos decorrentes do excesso de peso, e isto dificultava o reconhecimento por parte da família como problema de saúde. Em suas con- cepções, a criança apresentava boa saúde, pois tinha apetite, realizava atividades físicas sem dificuldades e não apresentava doença aguda ou crônica associada.

Por outro lado, com a utilização da escala visual, pode-se identificar que as mães reconheciam o excesso de peso. Quando questionadas sobre qual das figuras melhor representava o corpo da criança, nove delas selecionaram a figura sete, e cinco a figura seis. Em relação à qual daquelas figuras a mãe gostaria que a criança se assemelhasse, quatro apontaram a figura anterior à selecionada como representativa do status corporal atual, quatro ansiavam que a criança diminuísse duas figuras, quatro almejavam três figuras anteriores à selecionada e outras duas referiram que desejavam que a criança permanecesse como estava.

Esses resultados demonstraram que a maioria das mães em estudo, ainda que negasse a obesidade como doença, aspirava à redução de peso da criança, sendo que algumas, inclusive, almejavam uma grande diminuição do peso corporal. Dentre as 14 mães incluídas no estudo, 12 assentiram no excesso de peso da criança na visualização da escala. Os relatos das outras duas mães mostraram a tendência que elas tinham de minimizar a problemática da obesidade na infância e, ao mesmo tempo, a relutância para aceitar que o filho está obeso, mesmo após o alerta de profissionais de saúde.

\footnotetext{
Ela está acima do peso uns quilos, mas eu não a enxergo gorda. Não a vejo tão obesa quanto falam. Porque levo ela no posto para pesar e diziam "Mãe, ela está obesa!", mas eu nunca enxerguei minha filha obesa (Mãe 12, 30 anos Filha, 7 anos).
}

Além de não reconhecerem a condição de obesidade como problema de saúde, uma das 
mães revelou acreditar que o excesso de peso se relacionava a um bom estado de saúde e que esta condição é característica de uma fase da vida da criança, que tende a regredir com o início da puberdade.

Ele nasceu magrinho, com três quilos e pouquinho. Mas, dei aquelas vitaminas para ele, foi quando começou a engordar. Minha mãe e minha avó me diziam: "Esse menino está muito magrinho!". Comecei a dar [as vitaminas] para ele e assim começou a engordar (Mãe 13, 29 anos - Filho, 9 anos).

Embora algumas mães não considerassem a obesidade infantil uma doença ou tivessem dúvidas em relação a isto, elas conseguiam assumir que determinadas queixas e embaraços no desenvolvimento de atividades cotidianas poderiam ser derivados do excesso de peso:

Se a obesidade é uma doença eu não sei, mas que ela acarreta um monte de doença, isso sim. Porque acho que se ela não estivesse gordinha como está, talvez o probleminha dela de não conseguir dormir e do ronco melhorava. Ela é fadigada (Mãe 4, 34 anos - Filha, 10 anos).

Às vezes ele reclama: "Mãe, vem me ajudar a colocar a bermuda, porque não estou conseguindo!". Mas por quê? Eu falo para ele, que ele está gordinho e que fica mais difícil de vestir a bermuda, porque a roupa para nas dobrinhas (Mãe 14, 31 anos - Filho, 7 anos).

Outras mães iam além e conseguiam vislumbrar a possibilidade de prejuízos para a saúde na vida adulta em decorrência da obesidade na infância:
Seique com a obesidade ele pode desenvolver diabetes, colesterol, pressão alta [...] Eaténo futuro pode trazer problemas tanto no psicológico, como no físico (Mãe 1, 28 anos - Filho, 9 anos).

Observou-se, portanto, que muitas mães deste estudo não consideravam a obesidade infantil como doença, embora algumas acreditassem que ela possa ser responsável pelo desenvolvimento de outras doenças. Algumas mães, inclusive, conseguem reconhecer os prejuízos que o excesso de peso pode trazer na qualidade de vida da criança e no futuro, considerando não apenas a esfera física, mas também a psicológica e social.

Desenvolvimento, manutenção e tratamento da obesidade infantil: o enfrentamento da família

Ao fazerem referência às condutas e estratégias utilizadas pela família para enfrentar a obesidade infantil e controlar o peso da criança, sobressaíram tentativas relacionadas à mudança de hábitos, principalmente em correspondência à alimentação e à prática de atividades físicas. Contudo, verificou-se que, essas transformações eram incipientes, pontuais e se circunscreviam à inclusão na dieta da criança de alimentos considerados saudáveis e a exclusão daqueles não saudáveis, além da redução da quantidade de cada alimento servido na refeição.

Quando ele janta é só uma vez, não deixo repetir. Agora, às vezes, como eu sei que ele vai querer repetir, eu coloco um pouco menos no prato. Nunca fui de perguntar para ele o que quer comer, eu coloco no prato e ele come (Mãe 14, 31 anos - Filho, 7 anos). 
A busca e a implementação de alternativas que poderiam contribuir para a redução de peso foram frequentes, porém, observou-se que nem sempre as estratégias adotadas pelas famílias eram corretas ou benéficas, como, por exemplo, pular ou substituir as principais refeições.

Hoje depois que busquei ele na escola, ele comeu três coxinhas pequenas de mandioca. Então hoje não vai jantar, se quiser comer alguma coisa, come banana. Tem outros dias também que ele não janta (Mãe 1, 28 anos - Filho, 9 anos).

Quando as estratégias de mudança alimentar não foram citadas pelas mães se devia ao fato delas não reconhecerem as fragilidades na alimentação de seus filhos. Nesses casos, acreditavam que os alimentos oferecidos eram mais saudáveis quando comparados à alimentação de outras crianças.

De onde vem isso [a obesidade]? Porque na minha casa não tem essas bobeiras de comida, tem criança que toma refrigerante todos os dias, que come doce, chocolate, salgadinhos, aqui não tem isso (Mãe 8,33 anos Filho, 8 anos).

Nessa direção, o relato a seguir mostra que, no geral, as famílias possuíam algum conhecimento sobre quais alimentos são saudáveis e quais devem ser consumidos com moderação, mas, muitas vezes, não tinham condições financeiras que Ihes possibilitassem adquirir os alimentos mais apropriados.

Fruta quando tem come. De duas semanas para cá, a gente só está comendo arroz branco. A salsicha e a cenoura que a minha filha te falou foi porque a vizinha aqui deu. Mas fruta, verdura, essas coisas é só quando dá para comprar (Mãe 3, 42 anos - Filha, 9 anos).

Além da busca por uma alimentação saudável, quando possível, outra estratégia utilizada pelas famílias para favorecer a redução de peso, era o incentivo à prática de atividades físicas que motivassem a criança e assim facilitassem o seu desenvolvimento. Porém, fizeram referência a algumas dificuldades para a sua realização, as quais eram financeiras ou decorrentes da falta de estrutura nos bairros.

$$
\begin{aligned}
& \text { O duro é que para praticar esportes } \\
& \text { aqui para nós é tudo longe. Eu sei que } \\
& \text { tem uns grupos de criança no centro, } \\
& \text { mas como que a gente fica indo para } \\
& \text { lá? É complicado (Mãe 6, } 28 \text { anos - Fi- } \\
& \text { Iho, } 6 \text { anos). }
\end{aligned}
$$

É válido salientar que as mudanças na rotina foram mencionadas pelas mães que reconheciam as complicações da obesidade infantil como um problema de saúde, e, em especial, nos casos em que a criança já manifestava alguma dificuldade decorrente do excesso de peso.

Fragilidades nos hábitos familiares foram mencionadas, notadamente em relação à alimentação, os quais, além de não contribuírem para a redução de peso da criança, ainda concorriam para piorar sua condição.
A alimentação não é muito saudável. É mais pão, batata frita, essas coisas. $\mathrm{E}$ doce! A gente come bastante doce (Mãe 2, 28 anos - Filho, 6 anos).

Por outro lado, além de reconhecer as falhas nos hábitos alimentares da família que poderiam auxiliar no desencadeamento da obesidade 
infantil, algumas mães também identificaram fatores que auxiliavam na manutenção dessa morbidade. Casos em que a família possuía um vínculo estressante, ou mesmo aqueles em que a criança era reprimida e desmotivada pelos pais foi revelado nas falas:

O pai dela é muito ignorante, é tudo nos gritos. Aqui é meio complicado. De vez em quando ele a chama de gorda, ou então ela coloca alguma roupa e ele fala "Credo!". Ela fica chateada (Mãe 3, 42 anos - Filha, 9 anos).

Ainda, foram evidenciadas atitudes que as mães consideravam de apoio às crianças, porém o modo como eram realizadas coadunavam para que a criança permanecesse na condição atual de obesidade. Em um caso, por exemplo, a mãe procurava fazer com que a filha aceitasse a obesidade como uma condição genética e irreversível, o que não contribuía para a mudança no estilo de vida familiar.

Falo para ela que ser gordinha não é saúde, mas também não é doença, que ela não tem que se sentir pior que os amiguinhos, porque não existe só ela de gorda, existe muita gente que é assim. O problema é que o pai e a avó também são obesos, é hereditário, não tem para onde ela correr, infelizmente. Por mais que ela feche a boca, nunca vai ser magrinha. É isso que tento passar para ela (Mãe 9, 41 anos - Filha, 8 anos).

Os relatos desta categoria demonstraram que a maioria das famílias se envolvia com as mudanças no estilo de vida e o controle da obesidade infantil. Entretanto, em alguns casos, o entendimento equivocado sobre a alimenta- ção, as condições financeiras e a resignação em aceitar a obesidade eram obstáculos para o enfrentamento da doença e a melhora no padrão de vida das crianças.

\section{DISCUSSÃO}

Admitir o excesso de peso infantil não é uma tarefa simples para os pais, como identificado neste e em outros estudos ${ }^{(3,5,8)}$. Em pesquisa realizada com as mães de crianças atendidas em Unidades Básicas de Saúde em um município do sudeste do Brasil, constatou-se que as mães de crianças com estado nutricional extremo - desnutrição ou sobrepeso -, apresentavam de cinco a onze vezes mais chances de classificar o estado nutricional da criança de maneira incorreta ${ }^{(5)}$.

Um estudo qualitativo realizado com pais de oito crianças obesas mostrou que cinco deles enxergavam a criança mais magra do que ela realmente era ${ }^{(9)}$. Além disso, investigação realizada nos Estados Unidos da América demonstrou que as próprias crianças com obesidade tinham dificuldade em reconhecer este estado ${ }^{(10)}$.

Os bloqueios em considerar o excesso de peso estão frequentemente relacionados ao não reconhecimento da obesidade como doença ou dos problemas de saúde que ela pode acarretar ${ }^{(8)}$. E, considerando o aumento da prevalência de obesidade em todo o mundo e em todas as faixas etárias, é possível que a mãe encare o excesso de peso das crianças como uma condição normal, sobretudo por acreditarem que a obesidade é de resolução espontânea por ocasião do início da adolescência ${ }^{(11)}$.

Percepções semelhantes também foram verificadas no presente estudo, sendo que as repercussões negativas da obesidade vivenciadas por algumas crianças serviram como alerta para os pais e os faziam reconhecer a obesidade como um problema. Neste momento, percebiam 
como necessário o enfrentamento da situação, o que os levava a buscar alternativas para redução de peso, com destaque para as mudanças na alimentação e o incentivo para prática de alguma atividade física.

A negação ou o desconhecimento sobre os efeitos deletérios da obesidade para a saúde são fatores que podem postergar a busca por ajuda profissional e o início do tratamento ${ }^{(4,9)}$. Deveras, essa ajuda é necessária, pois a obesidade pode provocar dificuldades respiratórias, disfunções ortopédicas, aumento do risco para fraturas, hipertensão arterial, resistência à insulina, entre outros $^{(12)}$.

Cabe salientar que a incidência, cada vez maior, de obesidade entre as crianças tem possibilitado que essas patologias também sejam diagnosticadas em faixas etárias cada vez mais jovens da população ${ }^{(13,14)}$. Exemplo disso é o aumento de casos de hipertensão arterial entre os escolares com sobrepeso e obesidade ${ }^{(15,16)}$.

O fato da mãe conseguir associar o excesso de peso corporal do filho com os problemas de saúde que a criança já exibe ou a possibilidade de vir a apresentar, constitui motivação para o início das transformações no estilo de vida da família, principalmente em relação à rotina alimentar $^{(9)}$. Os profissionais de saúde devem identificar esses conhecimentos e potencializá-los, para o adequado tratamento da obesidade, assim como, o serviço de saúde em parceria com a escola e a família devem identificar estratégias eficazes. No entanto, neste estudo, observa-se que as famílias agem de acordo com seu conhecimento empírico para o manejo da obesidade infantil, a intersetorialidade e a integralidade são aspectos inerentes na atenção à saúde da criança e deve ser considerada em relação à obesidade.

Contudo, nem sempre a mudança adotada no seio familiar é a mais adequada. Exemplo disto é o incentivo à substituição de refeições ou mesmo de não realizar alguma refeição, atitude não recomendada para o tratamento da obesidade, pois isto pode trazer prejuízos para a saúde e o desenvolvimento infantil ${ }^{(14)}$. A substituição de refeições por lanches quando solicitado pela criança, também firma um erro comum e, uma vez cedido, ela tenderá a repetir essa estratégia ${ }^{(17)}$.

Assim, é preciso ponderar a influência dos pais nas práticas alimentares dos filhos em longo prazo. A família é considerada a principal influência ambiental para a criança e o conhecimento que ela tem sobre os alimentos não advém apenas de suas experiências, mas também da observação do comportamento alimentar do outro, e, nesses casos, dado a proximidade, sobressaem as escolhas alimentares da família ${ }^{(18)}$.

Os relatos mostraram, ainda, que os obstáculos para estabelecer uma rotina saudável de alimentação para a criança podem extrapolar as questões disciplinares e envolver as condições financeiras da família. Destarte, os impedimentos para obtenção de alimentos já fora relatada em outro estudo, em que as mães descreveram o alto preço de frutas e legumes como um empecilho para a aquisição desses produtos ${ }^{(19)}$.

Extrapolando as questões alimentares, outro aspecto importante a ser considerado no desenvolvimento e na manutenção da obesidade é a não realização de atividade física em quantidade e qualidade necessárias. Isto acaba por tornar-se um círculo vicioso, porque com ausência de atividade física, aumente-se o peso corporal, o qual desencadeia obstáculos que fazem com que a criança se sinta desmotivada a praticar atividade física, agravando ainda mais o quadro de obesidade. Deveras, as crianças com excesso de peso são notoriamente as que apresentam os níveis mais baixos de coordenação motora quando comparadas às crianças eutróficas, o que desmotiva a prática de atividades físicas regulares ${ }^{(20)}$. 
As adversidades enfrentadas pelas crianças durante a prática de atividades físicas são, em alguns casos, reconhecidas pelas mães, que mencionaram, além da deficiência de coordenação motora, a fadiga. Contudo, as mães que admitem a importância do exercício físico para a saúde de seus filhos buscam alternativas para motivá-los e incentivá-los. Ressalta-se, no entanto, que, como mencionado pelas participantes, não existem programas regulares de atividade física disponíveis nos bairros, ou seja, mesmo que as famílias reconheçam essa necessidade, 0 entrave está no acesso a esse serviço pela falta de oferta.

A família também pode intervir no desenvolvimento e na continuidade da obesidade na infância de outras maneiras, tais como, o tipo de vínculo estabelecido entre os membros da família e a criança. Quando são evidenciadas relações conflituosas na família, com vínculos frágeis e estressantes, transmite-se às crianças a insegurança emocional, de tal modo que a família deixa de ser reconhecida como um ambiente acolhedor e seguro ${ }^{(8,20)}$. Assim, forma-se uma lacuna na função parental, que pode repercutir negativamente no desenvolvimento da criança e refletir no surgimento de doenças alimentares ${ }^{(8,19)}$.

Faz-se necessário, também, levar em consideração as características genéticas da criança que podem predispor à obesidade. Nesse sentido, uma das mães reconhece a predisposição genética da filha para a obesidade e estimula a criança a se aceitar dessa maneira. Apesar de ser uma atitude positiva, em que a mãe preza pelo bem-estar do filho, ao mesmo tempo, pode desencorajá-lo a buscar alternativas para a redução do peso, por acreditar que, sendo um fator hereditário, não haverá regressão.

Por fim, para o êxito das intervenções que têm por objetivo reverter o quadro de obesidade na infância, se faz necessária a participação efeti- va e o envolvimento de toda a família, principalmente dos pais, que são os principais cuidadores e educadores da criança nos primeiros anos de vida $^{(8,19)}$. Além da família, é importante a participação dos demais contextos em que essa criança se insere, a começar pela escola e nos últimos anos, a partir do Programa Saúde na Escola, é preciso que a articulação entre saúde e educação se tornem efetivas, para juntamente com a família, traçar estratégias que rompam com o mecanismo da obesidade. Assim, a influência exercida pelos pais e pela sociedade são significativas para que a criança se aproprie de práticas mais saudáveis ${ }^{(5)}$, porém, além disso, também é relevante o apoio que a família transmite para que a criança se sinta segura e encorajada para o enfrentamento da obesidade. Assim, faz-se necessário que as relações familiares sejam sólidas, constituindo um ambiente acolhedor e seguro ${ }^{(8)}$.

\section{CONCLUSÃO}

Os resultados da pesquisa revelaram que a maioria das mães reconhece o excesso ponderal dos filhos, porém, nem sempre esse excedente é considerado um problema capaz de interferir em seu processo saúde-doença. A obesidade, portanto, em geral, é percebida como doença apenas quando desencadeia complicações, o que é preocupante, pois isso atrasa o diagnóstico da doença e o início do tratamento. É notório também que algumas crianças já enfrentam efeitos negativos da obesidade, principalmente na execução de tarefas simples do dia a dia e durante as práticas esportivas e, nestes casos, as famílias reconhecem mais facilmente a obesidade como problema de saúde se comparadas com aquelas crianças em que os reflexos negativos ainda não se manifestaram.

Assim, espera-se que os resultados deste estudo consigam sensibilizar profissionais de 
saúde e da educação, bem como seus gestores, subsidiando a prática daqueles que lidam com as crianças e com as famílias que convivem com a obesidade infantil. E sugere-se ao profissional que indague à família sobre as possíveis mudanças já realizadas ante o problema da obesidade, contribuindo, assim, para a elaboração de novas e criativas estratégias para o enfrentamento da obesidade infantil no seio familiar, considerando os aspectos psicoemocionais e sociais que envolvem o problema.

Por fim, é importante ressaltar que, por se tratar de um estudo de natureza qualitativa, não é viável fazer generalizações de seus resultados e a comparabilidade deve ser procedida com cautela. Portanto, sugere-se que novas investigações, mais amplas e com outras abordagens metodológicas, incluindo outros membros da família, a criança obesa, profissionais de saúde e educadores, sejam realizadas, de modo a propiciar maior compreensão da forma como a família e a criança compreendem e enfrentam a questão da obesidade infantil.

\section{REFERÊNCIAS}

1. Organización Mundial de la Salud - OMS. Estadísticas Sanitarias Mundiales una Mina de Información sobre Salud Pública Mundial. 2014 [acesso em 2014 out. 15]. Disponível em: http:// apps.who.int/iris/bitstream/10665/112817/1/ WHO_HIS_HSI_14.1_spa.pdf

2. Williams PA, Cates SC, Blitstein JL, Hersey J, Gabor $\mathrm{V}$, Ball M. Nutrition-education program improves preschoolers' at-home diet: a group randomized trial. J Acad Nutr Diet. 2014; 114(7): 1001-8.

3. Rietmeijer-Mentink M, Paulis WD, Middelkoop $M$, Bindels PJEC, Wouden J. Difference between parental perception and actual weight status of children: a systematic review. Matern Child Nutr. 2013; 9(1): 3-22.

4. Guevara-Cruz $M$, Serralde-Zúñiga $A E$, Vázquez-Vela MEF, Galicia LB, Islas-Ortega L. Association between maternal perceptions and actual nutritional status for children in a study group in Mexico. Nutr Hosp. 2012; 27(1): 209-12.

5. Duarte LS, Fujimori E, Toriyama ATM, Palombo CNT, Miranda PPL, Borges ALV. Maternal perception of their child's nutritional status at less than three years old. Rev Esc Enferm USP. 2016; 50(5):771-778.

6. Minayo MCS. O desafio do conhecimento: pesquisa qualitativa em saúde. 13. ed. São Paulo: Abrasco; 2013.

7. Tiggemann M, Wilson-Barret E. Childrens's figure ratings: relationship to self-esteem and negative stereotyping. Inter J Eat Disord. 1998;23(1):83-8.

8. Moraes PM, Dias CMSB. Nem só de pão se vive: a voz das mães na obesidade infantil. Psicol Cienc Prof. 2013; 33(1): 46-59.

9. Camargo APPM, Barros Filho AA, Antonio MARGMA, Giglio JS. A não percepção da obesidade pode ser um obstáculo no papel das mães de cuidar de seus filhos. Ciênc Saúde Coletiva. 2013; 18(2): 323-33.

10. Economos CD, Bakun PJ, Herzog JB, Dolan PR, Lynskey VM, Markow D. et al. Children's perceptions of weight, obesity, nutrition, physical activity and related health and socio-behavioural factors. Public Health Nutr. 2012; 17(1): 170-8.

11. Francescatto C, Santos NS, Coutinho VF, Costa RF. Mothers' perceptions about the nutritional status of their overweight children: a systematic review. J Pediatr. 2014; 90(4):332-43.

12. World Health Organization - WHO. Obesity and overweight. Atualizado em mar. 2013 [acesso em 2013 set 20]. Fact Sheet $n^{\circ} 311$. Disponível em: <http://www.who.int/mediacentre/factsheets/ fs311/en/index.html>.

13. Cunningham SA, Kramer MR, Narayan KMV. Incidence of childhood obesity in the United States. N Engl J Med. 2014; 370(2): 403-11.

14. Delgado MF, Frazão CMFQ, Fernandes MICD, Medeiros ABA, Lúcio KDB, Lira ALBC. Factors associated with cardiovascular disease in children and adolescents: a cross-sectional study. Online braz j nurs [internet] 2015 [cited 2016 Jun 10]; 14 (2): 168-77. Available from: http://www.objnursing. uff.br/index.php/nursing/article/view/5126

15. Elkiran O, Yilmaz E, Koc M, Kamanli A, Ustundag $B$, Ilhan N.The association between intima media 
thickness, central obesity and diastolic blood pressure in obese and owerweight children: $A$ cross-sectional school-based study. Int J Cardiol. 2013; 165 (3): 528-32.

16. Passos-Santos JP, Prati ARC, Molena-Fernandes CA. Associação entre pressão arterial e indicadores de obesidade geral e central em escolares. Cienc Cuid Saude. 2013; 12(1): 146-54.

17. Associação Brasileira para o Estudo da Obesidade e da Síndrome Metabólica - ABESO. Dicas: 10 erros que não devemos cometer na educação alimentar da criança [online]. 2013 [acesso em 2014 ago 13]. Disponível em: <http://www.abeso. org.br/pagina/27/::+10+erros+que+nao+deve mos+cometer+na+educacao+alimentar+da+c rianc.shtml>.

18. Kim HS, Park J, Park KY, Lee MN, Ham OK. Parent Involvement Intervention in Developing Weight Management Skills for both Parents and Overweight/Obese Children. Asian Nurs Res. 2016; 10(1): 11-7.

19. Lindsay AC, Ferarro M, Franchello A, Barrera RL, Machado MMT, Pfeiffer ME, Peterson KE. Child feeding practices and household food insecurity among low-income mothers in Buenos Aires, Argentina. Ciênc Saúde Coletiva. 2012; 17(3):661-9.

20. Hondt ED, Deforche B, Gentier I, Bourdeaudhuij I, Vaeyens R, Philippaerts R. et al. A longitudinal analysis of gross motor coordination in overweight and obese children versus normal-weight peers. Int J Obes. 2013; 37(1): 61-7.
Todos os autores participaram das fases dessa publicação em uma ou mais etapas a seguir, de acordo com as recomendações do International Committe of Medical Journal Editors (ICMJE, 2013): (a) participação substancial na concepção ou confecção do manuscrito ou da coleta, análise ou interpretação dos dados; (b) elaboração do trabalho ou realização de revisão crítica do conteúdo intelectual; (c) aprovação da versão submetida. Todos os autores declaram para os devidos fins que são de suas responsabilidades o conteúdo relacionado a todos os aspectos do manuscrito submetido ao OBJN. Garantem que as questões relacionadas com a exatidão ou integridade de qualquer parte do artigo foram devidamente investigadas e resolvidas. Eximindo, portanto o OBJN de qualquer participação solidária em eventuais imbróglios sobre a matéria em apreço. Todos os autores declaram que não possuem conflito de interesses, seja de ordem financeira ou de relacionamento, que influencie a redação e/ou interpretação dos achados. Essa declaração foi assinada digitalmente por todos os autores conforme recomendação do ICMJE, cujo modelo está disponível em http://www. objnursing.uff.br/normas/DUDE_final_13-06-2013.pdf

Recebido: 08/26/2016

Revisado: 07/12/2018

Aprovado: 07/12/2018 